\title{
ESTUDO COMPARATIVO ENTRE A HISTÓRIA DA CONTABILIDADE TRADICIONAL E A SUA NOVA HISTÓRIA
}

\author{
Comparative study between the history of traditional \\ accounting and its new history
}

Estudio comparativo entre la historia de la contabilidad tradicional y su nueva historia

\author{
Paulo Schmidt ${ }^{1}$ \\ Júlia de Medeiros Gass ${ }^{2}$
}

\section{RESUMO}

Desde o início de sua existência, a Contabilidade seguiu os passos evolutivos da sociedade. Inicialmente tudo era registrado de modo precário, mas, a partir do surgimento da escrita e dos números, os registros contábeis tornaram-se mais desenvolvidos e complexos. Esse processo evolutivo fez com que escolas de pensamentos contábeis se sucedessem através da história, especialmente com visóes tradicionais, seguindo os preceitos sociais e políticos de sua época. Porém, a partir de 1929, surgiu uma nova perspectiva histórica para a contabilidade com o aparecimento da chamada Nova História da Contabilidade ou História Crítica, liderada por uma nova corrente de pensadores com ideias contrárias as apresentadas pelos tradicionalistas. A partir desse novo momento, este estudo foi desenvolvido com o objetivo de apresentar quais as características que distinguem a Nova História da Contabilidade (NHC) da História Tradicional da Contabilidade (HTC). Para tanto, foi realizada uma análise descritiva e documental sobre a NHC e a HTC, aplicando-se uma abordagem qualitativa. $\mathrm{O}$ resultado indica que não existe consenso sobre esse processo evolutivo e que, ainda existem divergências significativas entre os defensores de cada corrente histórica. As principais contribuições do estudo estão relacionadas com o entendimento de que essa nova concepção sobre a história pode influenciar significativamente o foco de pesquisas sobre Contabilidade.

PALAVRAS-CHAVE: História. História tradicional da contabilidade. Nova história da contabilidade.

1 Doutor em Controladoria pela Universidade de São Paulo; professor titular do Departamento de Ciências Contábeis e Atuariais da Universidade Federal do Rio Grande do Sul. pschmidt@ufrgs.br.

2 Pós-graduada em Gestão Empresarial - Instituto Federal do Rio Grande do Sul; Graduada em Ciências Contábeis - Universidade Federal do Rio Grande do Sul - UFRGS; Graduada em Administração de Empresas - Rede Metodista do Sul - IPA. juliamgass@yahoo.com.br. 


\begin{abstract}
From the beginning of its existence, Accounting has followed the evolutionary steps of society. Initially everything was recorded precariously, but from the onset of writing and numbers, accounting records became more developed and complex. This evolutionary process has led schools of accounting thinking to succeed each other through history, especially with traditional views, following the social and political precepts of their day. However, from 1929 a new historical perspective for accounting appeared with the emergence of the so-called New Accounting History or Critical History, led by a new chain of thinkers with ideas contrary to those presented by traditionalists. From this new moment, this study was developed with the purpose of presenting the characteristics that distinguish the New Accounting History (NAH) from the Traditional Accounting History (TAH). For this, a descriptive and documentary analysis was performed on $\mathrm{NAH}$ and TAH, applying a qualitative approach. The result indicates that there is no consensus on this evolutionary process and that there are still significant divergences between the proponents of each historical current. The main contributions of the study are related to the understanding that this new conception about history can significantly influence the focus of research on Accounting.
\end{abstract}

KEYWORDS: History. Traditional accounting history. New accounting history.

\title{
RESUMEN
}

Desde el comienzo de su existencia, la Contabilidad siguió los pasos evolutivos de la sociedad. Al principio todo era registrado precariamente, pero desde la aparición de la escritura y números, registros de contabilidad se convirtió en más desarrollado y complejo. Este proceso evolutivo ha hecho escuelas de pensamientos de contabilidad tuvisteis éxito a lo largo de la historia, especialmente con vistas al tradicionales, siguiendo los preceptos sociales y políticos de su tiempo. Sin embargo, en 1929, surgió una nueva perspectiva histórica para la contabilidad con la aparición de la llamada Nueva Historia de la Contabilidad o Historia Crítica, dirigido por una nueva corriente de pensadores con ideas que compiten con las presentadas por tradicionalistas. A partir de este momento nuevo, este estudio fue desarrollado con el objetivo de presentar cuáles son las características que distinguen a la Nueva Historia de la Contabilidad (NHC) de la Historia Tradicional de la Contabilidad (HTC). Para eso, un análisis descriptivo y documental fue realizado sobre la NHC y la THC, aplicándose un enfoque cualitativo. El resultado indica que no existe consenso sobre este proceso evolutivo y que hay todavía diferencias entre los defensores 
de cada corriente histórica. Las principales aportaciones del estudio se relacionan con la comprensión de este nuevo concepto en la historia puedan afectar significativamente el enfoque de las investigaciones en la contabilidad.

PALABRAS CLAVE: Historia. Historia Tradicional de la Contabilidad. Nueva Historia de la Contabilidad.

Data de submissão: 03/04/2018

Data de aceite: $17 / 07 / 2018$

\section{INTRODUÇÃO}

O tema História representa um dos principais tópicos nos atuais estudos no campo das Ciências Sociais, apesar de serem escassos os estudos históricos voltados para a área da Contabilidade, especialmente no Brasil. Como defendem Padilha e Borenstein (2005, p. 576): “é possível fazer sentido no mundo sem abordar a questão da história"?

Apesar dos estudos históricos serem mais raros do que em outras áreas de interesse contábil, no mundo existem periódicos que publicam exclusivamente estudos históricos de Contabilidade, como é o caso da norte-americana The Accounting Historians Journal, que iniciou suas publicaçóes em 1974, da inglesa Accounting History, que passou a publicar em 1996, da espanhola De Computis - Revista Española de Historia de la Contabilidad, que começou suas publicaçóes em 2004 e da inglesa Accounting History Review, que desde 1990 passou a publicar artigos em história da contabilidade (SCHMIDT e SANTOS, 2017).

No Brasil, mesmo não havendo nenhuma revista que se dedique exclusivamente à publicação de artigos de história da contabilidade, existem alguns pesquisadores que publicam nessa área, como é o caso de Silva (2017), Schmidt e Santos (2017), Miranda et al. (2013), Peleias et al. (2007), Iudícibus, Martins e Carvalho (2005), Ricardino Filho e Martins (2003), dentre outros.

As pesquisas na área da histórica, como defende Barros (2011), têm se tornado mais complexas nos últimos anos, especialmente, considerando que o próprio conhecimento científico tem buscado mais especialidades nos processos de pesquisa.

Essa evolução nas pesquisas históricas, também repercutiu diretamente no próprio estudo da história da contabilidade, principalmente a partir do surgimento da chamada Nova História. Como destaca Burke (1992), as pesquisas histórias passam a direcionar seus focos para toda atividade humana, não apenas para os grandes homens e líderes mundiais, mas para as opiniōes das pessoas comuns, fazendo com que a história passasse a ser explicada por outras fontes e náo apenas por documentos tradicionais, onde o próprio historiador passou a entender a dificuldade de explicar como os fatos realmente aconteceram. 
Esse processo evolutivo de uma visão tradicional para uma nova visão da Contabilidade foi denominado por Carnegie (2014) como a transição da História da Contabilidade Tradicional (HCT) para a Nova História da Contabilidade (NHC).

O surgimento da chamada Nova História da Contabilidade, conforme Esteve (1997), pode ser considerado um dos acontecimentos mais importantes dos últimos anos na Contabilidade. Assim, essa nova visão baseou sua pesquisa em várias disciplinas sociais para fazer uma "história total", ou seja, uma história única, mas tendo a influência de outras áreas. Ela considera que "tudo tem um passado que, em princípio, pode ser reconstruído com o resto do passado" (Burke, 1992).

$\mathrm{O}$ estudo da NHC tem despertado o interesse de vários pesquisadores do mundo, objetivando entender pontos como o significado dessa transição, seus principais conceitos, quais são as implicaçóes para o estudo da História da Contabilidade, dentre outros. Dentre os pesquisadores, podem ser destacados Carnegie (2014), Bertalan e Napier (2013), Carmona, Ezzamel e Gutiérrez (2004) e Miller, Hopper e Laughlin (1991).

A partir desses e de outros estudos contábeis com abordagem evolutiva da perspectiva tradicional para a nova história da contabilidade, esse trabalho busca contribuir para o entendimento da seguinte questáo: quais as principais diferenças conceituais entre o estudo da História Tradicional da Contabilidade e da Nova História da Contabilidade?

Esse artigo inicia com a apresentação do intento que será desenvolvido, seguido dos estudos relacionados com os principais conceitos de História Tradicional e da Nova História da Contabilidade, dos procedimentos metodológico utilizados na pesquisa, e encerra com a apresentação das principais diferenças conceituais entre os dois enfoques históricos de análise da Contabilidade e as considerações finais.

\section{FUNDAMENTOS TEÓRICOS SOBRE HISTÓRIA}

O objetivo desta seção é apresentar o conceito e a caracterização da história como um ramo do conhecimento humano, da história tradicional, assim como da nova história.

\subsection{HISTÓRIA COMO UM RAMO DO CONHECIMENTO HUMANO}

Segundo Maia et al (2011, p. 139) a história "que significa em grego "ver", "começou com um relato, a narração daquele que pode ouvir e vêm mantendo este aspecto de "história testemunho" no processo de seu desenvolvimento. Os autores ainda mencionam que a história "é constituída pela expe- 
riência humana vivida integral e socialmente, numa constante contradição de ideias, necessidades e aspirações que se manifestam num movimento de "fazer, desfazer e refazer" (MAIA et al, 2011, p. 139).

Dessa maneira, "a história é ciência e não arte, consistindo a tarefa do historiador não em evocar ou reviver o passado [...] mas sim em narrar/descrever os acontecimentos deste passado tal como eles realmente se passaram" (FALCON, 1997, p. 66). Corroborando com o autor, Maia et al citam que:

A constituição de bibliotecas e arquivos e elaboração de métodos de crítica científica vêm conferindo a história, desde o século XVII, o "status" de ciência. O fato de não "existir história sem erudiçáo” vem sendo questionada no século XX a partir da crítica de noção de fato histórico, que é definido como objeto que não é acabado, pois resulta da construção do historiador (MAIA et al, 2011, p. 139).

A partir da história, tem-se a historiografia que se trata de um ramo da ciência que estuda a evoluçáo no desenvolvimento histórico global. A ideia é da história como estudo do homem no tempo por meio da redefinição de conceitos fundamentais como documento, fato histórico e tempo (Costa et al, 2010). Os autores citam ainda, as principais características da historiografia:

a) discurso histórico construído em função de uma epistemologia empirista; b) análises de curtos períodos temporais; c) foco no âmbito político e na atribuição de relevância aos eventos conjunturais e personagens específicos (história baseada em ideias e açôes de alguns poucos agentes históricos individuais) (COSTA et al, 2010, p. 293).

Durante o começo do século XX "manteve-se quase inalterada a hegemonia da historiografia política tradicional, começando o seu declínio somente a partir dos anos 1930 com a história social e a partir dos anos 1970 com a nova história" (Costa et al, 2010, p. 293).

No século XX, a historiografia renovada promove um profundo questionamento tanto da noção de fato histórico (não mais um objeto dado e acabado e sim construção do historiador) quanto da noção de documento (noção ampliada e não mais considerado algo objetivo e inocente). A própria ausência de documentos passa a ser significativa, pois elucida que estes são sempre produtos de uma sociedade que os fabricou segundo relaçôes de dominação e poder (COSTA et al, 2010, p. 294).

Esse movimento em direçáo a um novo tipo de história foi iniciado e conduzido por Marc Bloch e Lucien Febvre, em 1929, com a publicação do primeiro número da revista dos Annales d'Histoire Économique et Sociale. Foi o início da disciplina de história às temáticas e métodos das outras ciências humanas por meio da formulaçáo de novos problemas, novos métodos e novas abordagens da pesquisa histórica (CASTRO, 1997). 
Assim, as maiores dificuldades para os novos historiadores são as que estão relacionados às fontes e aos métodos: "quando os historiadores começaram a fazer novos tipos de perguntas sobre o passado, para escolher novos objetos de pesquisa, tiveram de buscar novos tipos de fontes, para suplementar os documentos oficiais" (BURKE, 1992, p. 25).

Esse novo grupo de pesquisadores tem estudado ideias contrárias as clássicas, dissociando-se das escolas tradicionais, o que gerou a nova história. "O movimento de mudança surgiu a partir de uma percepção difundida da inadequação do paradigma tradicional. Esta percepção da inadequação só pode ser compreendida se olharmos além do âmbito do historiador, para as mudanças no mundo mais amplo" (Burke, 1992, p.7).

Portanto identificar as visóes provenientes do debate entre as perspectivas da história tradicional e da história nova pode contribuir para: "a) melhor compreensão dos fenômenos administrativos; b) formação de pesquisadores mais conscientes de seus caminhos de pesquisa e c) fortalecimento da interdisciplinaridade por meio da criação de vínculos mais profundos entre as áreas" (Costa et al, 2010, p. 290).

\subsection{HISTÓRIA TRADICIONAL}

Segundo Le Goff (1992, p. 9), a história começou como uma história relato ou como testemunho, assim como "a narração daquele que pode dizer 'eu vi, senti'”. Dessa forma a ciência histórica passou a priorizar a reunião de documentos escritos, transformando-os em testemunhos.

A visão tradicional dedicou seus esforços para compartilhar a história com a "história oficial", como uma história cujo objeto principal de investigação era os fatos políticos. Sua atenção foi direcionada exclusivamente por instituiçóes como o Estado, a Igreja e a Guerra, o que resultou em histórias centradas nas façanhas dos "Grandes Homens (aqueles que verdadeiramente fazem história), tratando-os como eventos únicos (às vezes predestinados) que dão novas orientaçôes para a vida de uma naçâo ou de uma sociedade" (MARTÍN, 2006, p. 189).

A história tradicional é caracterizada como:

Uma narrativa dos acontecimentos políticos e militares, apresentada como a história dos grandes feitos de grandes homens e legitimada por uma visão centralizada e institucionalizada do poder, a história política tradicional foi definindo e disseminando seus objetos, princípios e métodos mesmo diante de tentativas de contestação a esse tipo de narrativa (COSTA et al, 2010, p. 296).

Dessa forma, essa visão não se vinculou à vida cotidiana dos homens, importando apenas com os grandes fatos e os grandes personagens, uma história conclusa aos grandes feitos e às grandes narrativas, o que era um 
movimento quase que inerte (CLEMENTE, 2011). Assim, perdurou durante muito tempo como "objeto por excelência na produção histórica" (FALCON, 1997, p. 65).

Esta abordagem considera que a história podia ser vista como uma série de decisóes econômicas racionais e que tinha como função o ensinamento por meio de exemplos reais e ilustres, o que levaram ao progresso que foi feito até hoje. Vale destacar que esta visão é a predominante da história, em que considera uma série de eventos encadeados até o fim (MARTíN, 2006).

O paradigma tradicional pregava que a disciplina devia dizer respeito essencialmente à política. "História é política passada; política é história presente", nas palavras de Sir John Seeley (BURKE, 1992). Desse modo, essa dimensão política era vista a partir do Estado e dedicava às grandes homens, batalhas e guerras, considerando predominantemente aqueles documentos oficiais.

\subsection{NOVA HISTÓRIA}

Durante o século XX surgiram novas concepçóes do conhecimento histórico tradicional, repercutindo em diversos outros caminhos para a pesquisa histórica, através de diferentes abordagens e problemas. "Os autores dessas novas concepçôes, mesmo que não comunguem de uma homogeneidade de ideias e posicionamentos perante a História, alinham-se a uma corrente historiográfica que passou a denominar-se Nova História” (MAIA et al, 2011, p. 139).

Este novo paradigma "possibilitou historicizar novos temas que antes não eram pesquisados e novas metodologias e técnicas para a análise das fontes concorrendo para o melhor desempenho da investigação". [...] Assim, a história também pode ser revista ganhando novas respostas historiográficas e outros temas podem ser investigados "provando que tudo e todos têm uma história a ser desvendada e reconhecida" (MAIA et al, 2011, p. 140).

Essa visão também tem sido chamada de história vista de baixo, pois se trata de uma história relacionada com o movimento, às mudanças econômicas e sociais, com a sociedade, e entre os outros; assim sem desvalorizar os "grandes feitos" que não deixam de ser importantes. Esta pretensão da história total requer fontes documentais que não sejam apenas oficiais, mas produzidas por setores que "não tinham história" e, portanto, tendem a investigar história oral, estatística, etc. (MARTÍN, 2006).

Assim, a história vista de baixo considera as opinióes das pessoas comuns com suas experiências da mudança social e da história da vida cotidiana, o que difere da história tradicional, que vê os fatos "de cima" concentrados nos grandes feitos, nos grandes homens e na elite.

Conforme Maia et al (2011, p. 139) a nova história "tem uma tradição própria, a dos fundadores da revista Annales d'histoire économique et sociale, 
editada a partir de 1929, e faz uma crítica à noção de fato histórico, como se houvesse uma "realidade histórica acabada que se entregaria por si só ao historiador". Sobre os Annales, os autores mencionam:

Os primeiros historiadores dos Annales são vistos como responsáveis por uma nova concepção historiográfica, pela ampliação da noção de "fonte histórica", pela valorização de uma "história estrutural” em oposição à "história factual”, por uma prática interdisciplinar e por uma série de outras contribuiçóes (MAIA et al, 2011; p. 139).

Já Burke (1992) cita:

Para muitas pessoas, a nova história está associada à Lucien Febvre e a Marc Bloch, que fundaram arevista Annales em 1929 para divulgar sua abordagem, e na geração seguinte, a Fernand Braudel. Na verdade,seria difícil negar a importância do movimento para a renovação da história liderado por esses homens (BURKE, 1992, p. 5).

Associada à chamada École des Annales, "La nouvelle histoire", expressão francesa de A Nova História, é o título de uma coleção de ensaios do francês Jacques Le Goff. Apesar de não ter uma definição exata, este movimento é a união daqueles que se opóem as ideias tradicionais. É a história escrita como uma reação contra o "paradigma” clássico (BURKE, 1992). "É por isso difícil apresentar mais que uma descrição vaga, caracterizando a nova história como história total (histoire totale) ou história estrutural. [...] Em outras palavras, definir a nova história em termos do que ela não é, daquilo a que se opóem seus estudiosos" (BURKE, 1992, p. 2).

Poderíamos também chamar este paradigma de a visão do senso comum da história, não para enaltecê-lo, mas para assinalar que ele tem sido com frequência - com muita frequência - considerado $a$ maneira de se fazer história, ao invés de ser percebido como uma dentre várias abordagens possíveis do passado (BURKE, 1992, p. 2).

Os novos historiadores estão enfrentando problemas de definição porque eles "estáo avançando em território não familiar. Como normalmente fazem os exploradores de outras culturas, eles começam com uma espécie de imagem negativa daquilo que estão procurando" (Burke, 1992, p. 6). Entretanto, outros obstáculos surgiram:

Os maiores problemas para os novos historiadores, no entanto, são certamente aqueles das fontes e dos métodos. Já foi sugerido que quando os historiadores começaram a fazer novos tipos de perguntas sobre o passado, para escolher novos objetos de pesquisa, tiveram de buscar novos tipos de fontes, para suplementar os documentos oficiais. Alguns se voltaram para a história oral; outros à evidência das imagens; outros à estatística (BURKE, 1992, p. 8). 
Este novo paradigma faz com que o pesquisador não utilize apenas um simples modelo de análise, mas sim, que ele busque uma conexão entre a teoria e a filosofia, para agregar valor positivo à sua pesquisa, além de trazer inúmeras possibilidades de vantagens, como uma melhor interpretaçáo e compreensão dos significados e sentidos dos eventos e contribuir para o desenvolvimento e construção do conhecimento histórico (MAIA et al, 2011).

\section{PROCEDIMENTOS METODOLÓGICOS}

A pesquisa realizada neste estudo foi classificada quanto aos seguintes aspectos: pela forma de abordagem do problema; de acordo com seus objetivos; e com base nos procedimentos técnicos utilizados.

Quanto à forma de abordagem do problema, a pesquisa é qualitativa. Tal pesquisa de acordo com o Minayo (1994, p. 21), "responde a questóes muito particulares. Ela se preocupa nas ciências sociais, com um nível de qualidade que não pode ser quantificado”. Já Lima (2008, p. 40) destaca que a "abordagem qualitativa pressupóe a investigação de aspectos sociologicamente construídos e que, por isso, não são facilmente mensuráveis”. Bauer e Gaskell (2012, p. 24) também demonstram a importância da pesquisa qualitativa:

A mensuração dos fatos sociais depende da categorização do mundo social. As atividades sociais devem ser distinguidas antes que qualquer frequência ou percentual possa ser atribuído a qualquer distinção. É necessário ter uma noção das distinçôes qualitativas entre categorias sociais, antes que se possam medir quantas pessoas pertencem a uma ou outra categoria (BAUER e GASKELL, 2012, p. 24).

Ou seja, a pesquisa foi classificada nesse aspecto, pois os dados que foram analisados, não eram numéricos, mas sim de diferentes abordagens, o que possibilitou ao pesquisador informaçóes mais aprofundadas e maior liberdade na condução dos documentos a fim de obter melhores respostas, aprofundando os pontos que se considerarem mais importantes para o cumprimento dos objetivos do estudo.

De acordo com objetivos propostos, a pesquisa é descritiva. Este tipo de pesquisa tem como finalidade descrever características de uma determinada população ou fenômeno ou estabelecer relaçôes entre variáveis (GIL, 2009). Para Cervo e Bervian (1996, p. 49) "a pesquisa descritiva procura descobrir, com a precisão possível, a frequência com que um fenômeno ocorre, sua relação e conexão, com os outros, sua natureza e características, correlacionando fatos ou fenômenos sem manipulá-los".

A pesquisa em questão teve o objetivo de descrever e analisar as características que distinguem a NHC da HTC. Assim, quanto aos procedimentos técnicos utilizados, o estudo classificou-se como pesquisa documental. 
A estratégia de Pesquisa Documental é característica dos estudos que utilizam documentos como fonte de dados, informaçóes e evidências. [...] a pesquisa documental emprega fontes primárias, assim considerados os materiais compilados pelo próprio autor do trabalho, que ainda não foram objeto de análise, ou que ainda podem ser reelaborados de acordo com os propósitos da pesquisa (MARTINS e THEÓPHILO, 2009, p. 55).

Foi utilizado este tipo de procedimento, pois foi realizada a pesquisa em documentos e artigos publicados como fonte de dados, informaçôes e evidências. Dessa forma, o plano de coleta foi investigar documentos, livros e artigos publicados referentes ao assunto em questáo.

A análise de dados foi realizada através de uma análise de conteúdo. Já Bardin (1977, p. 42 apud VERGARA, 2006, p. 16) a define como:

Um conjunto de técnicas de análise das comunicaçóes visando obter, por procedimentos sistemáticos e objetivos de descrição do conteúdo das mensagens, indicadores (quantitativos ou não) que permitam a inferência de conhecimentos relativos às condiçóes de produção/recepção (variáveis inferidas) destas mensagens.

Para Vergara (2006), a análise de conteúdo é uma técnica de tratamento de dados, que busca identificar o que foi dito acerca de um determinado assunto e também pode ser utilizada tanto para fins exploratórios (de descoberta), quanto para fins de verificação para confirmar ou não hipóteses e suposiçóes preestabelecidas.

\section{A TRANSIÇÃO DA HISTÓRIA TRADICIONAL DA CONTABILIDADE PARA A NOVA HISTÓRIA DA CONTABILIDADE}

Esta seção apresenta a História Tradicional da Contabilidade, a Nova História da Contabilidade e as diferenças entre elas.

\subsection{HISTÓRIA TRADICIONAL DA CONTABILIDADE}

A História Tradicional apresenta uma dimensão técnica da contabilidade, que a prioriza como um sistema de mensuraçáo e comunicação de transaçóes econômicas para chegar a representaçōes verificáveis próximas à realidade. Por um longo período, essa visão técnica foi privilegiada com características de neutralidade e objetividade e utilidade para a tomada de decisóes (GOMES, 2008).

Como citado por Morgan e Willmott (1993, p. 8), "nesta visão, a contabilidade é incontestável porque é simplesmente medir ou relatar a realidade". Assim, cabe ressaltar que na contabilidade tradicional o lado social náo foi 
explorado, entretanto, não quer dizer que ele tenha sido ignorado, o fato é que não houve a mistura dos dois, da técnica e do social, ou não foi devidamente levado em consideração (GOMES, 2008).

"Ciente da importância do contexto e do meio ambiente, era natural para que os historiadores tradicionais da contabilidade julguem os registros contábeis históricos em termos de sua capacidade de fornecer informações úteis para a tomada de decisóes" (CARNEGIE e NAPIER, 1996, p.15).

A história da contabilidade seria pouco mais do que uma história de progresso em que a contabilidade evolui em resposta aos desenvolvimentos técnicos de um determinado período.

A contabilidade é relativa e progressiva. Os fenômenos que formam seu objeto estão em constante mudança. Os métodos mais antigos tornam-se menos efetivos em condiçóes alteradas, ideias anteriores tornam-se irrelevantes diante de novos problemas. Assim, as condiçóes circundantes geram novas ideias e estimulam os engenhosos para aconselhar novos métodos. E, como tal, ideias e métodos são bem sucedidos, eles, por sua vez, começam a modificar as condiçóes circundantes (LITTLETON, 1966, p. 361).

Assim, percebe-se nas escolas dos pensamentos contábeis que o progresso contábil está relacionado com os fatos ocorridos na economia. Conforme Canabarro (2008, p. 41) "as escolas históricas possuem características próprias, o que influenciou diretamente na concepção de historiografia, pois esta muda de acordo com cada uma". O autor ainda cita que elas representam a maneira "como os historiadores pensam, como formulam seus trabalhos de pesquisa e como constroem o próprio conhecimento histórico" (CANABARRO, 2008, p. 41).

A Contabilidade é tão antiga quanto a história da civilização humana. A sua evoluçáo está diretamente relacionada e ligada com a história política e econômica do mundo, caracterizando-se assim, como uma visão tradicional. (SÁ, 1997).

A História da Contabilidade divide-se, pois, em nítidos períodos, cada um servindo de base para demarcar as evoluçóes, embora a maior parte de nosso saber se tenha situado, apenas, no campo dos registros e demonstraçóes, em razão do imenso valor que a humanidade atribuiu à escrita, como arte, e ao poder da memória gravada que ela ofereceu como fonte de evidência, controle, base de decisáo e prova. A escrituração contábil nasceu antes mesmo que a escrita comum aparecesse, ou seja, o registro da riqueza antecedeu aos demais, como comprovam os estudos realizados sobre a questáo, na antiga Suméria. A História da Contabilidade, pois, percorre milênios, participando das diversas modificaçóes sobre o uso da riqueza e dos recursos sobre os meios de registro (SÁ, 1997, p. 11). 
Ao pensar na História da Contabilidade, surgem as escolas contábeis, em que se deve entender como se deu o surgimento e o contexto na época em que estavam inseridas. Percebe-se que elas estão relacionadas com os acontecimentos sociais, econômicos e políticos que ocorreram no mundo, e dessa maneira muitas delas, sofreram grandes influências desses fatos, o que consequentemente, fez com que se tornassem parte da história tradicional.

A história da contabilidade é tâo antiga quanto à própria história da civilização. "Está ligada às primeiras manifestaçōes humanas da necessidade social de proteção à posse e de perpetuação e interpretação dos fatos ocorridos com o objeto material de que o homem sempre dispôs para alcançar os fins propostos" (ZANLUCA e ZANLUCA, 2017, p. 01).

Não se sabe exatamente quando começaram os primeiros registros contábeis, mas se tem conhecimento que na época dos sumérios já havia alguns indícios, através de registros primitivos de pagamentos, em placas de barro. Com o passar do tempo, diversos outros povos como egípcios, romanos e entre outros, também tiveram a sua forma de anotar suas transaçóes.
Alguns historiadores relatam que os primeiros sinais da exis- tência das contas datam de aproximadamente 4.000 A. C.. Entretanto, antes disto, o homem primitivo, ao inventariar as primeiras ferramentas e instrumentos de caça e pesca disponí- vel, ao contar seus rebanhos, já estava praticando uma forma rudimentar de contabilidade (COTRIN et al., 2012, p. 45).

No início do século XIV, com as grandes navegaçóes, consequente do aumento do comércio que ocorria na Europa, veio junto à peste bubônica. Conhecida como peste negra, essa infecção matou mais de um terço da população em curto espaço de tempo. Devido a ela, a mão de obra começou a tornar-se escassa, pois já não havia quem trabalhasse. Aproveitando a situação, muitos trabalhadores começaram a cobrar mais por seus trabalhos, o que fez muitos deixarem o campo atrás de salários maiores. Os efeitos dessa doença e outros fatores resultaram no declínio do sistema feudal (SCHMIDT e SANTOS, 2006).

Com o passar do tempo, toda a instabilidade em que a Europa passou durante o século XIV, virou um novo período, que foi marcado por expansão e crescimento. $\mathrm{O}$ sistema feudal entrou em crise e os trabalhadores já não tinham mais interesses em voltar para os campos, pois estavam em busca de condiçóes e salários melhores, fazendo com que as cidades começassem a crescer, e junto com ela, o comércio. Assim o trabalho escravo cedia lugar ao trabalho assalariado, alterando-se as relaçóes de trabalho. Esse processo gerou a acumulação de capital, tornando os registros mais complexos (SCHMIDT e SANTOS, 2006).

A partir desse momento, o comércio começa a se desenvolver devido a necessidade de tentar atender a toda nova população que estava se desenvolvendo e ao interesse dos comerciantes em lucrar mais. Em razão das intensas 
vendas e trocas que estavam acontecendo, cresce ainda mais as relaçóes econômicas, surgindo pequenos e grandes comerciários, que sentem a necessidade de fazer registros e anotaçóes sobre as combinaçôes feitas entre eles.

Foi pensando no futuro, devida a preocupação em ter que saber de todos seus bens, rendimentos, produção e oportunidades de crescimento de seus negócios, que levou o homem a fazer os seus primeiros registros, e assim, mais tarde surgindo à necessidade do controle (COTRIN et al., 2012).

$$
\begin{aligned}
& \text { "À medida que o homem começava a possuir maior quantida- } \\
& \text { de de valores, preocupava-lhe saber quanto poderiam render } \\
& \text { e qual a forma mais simples de aumentar as suas posses; tais } \\
& \text { informaçóes náo eram de fácil memorizaçáo quando já em } \\
& \text { maior volume, requerendo registros (ZANLUCA e ZANLU- } \\
& \text { CA, 2017, p. 01). }
\end{aligned}
$$

Em virtude dessa maior preocupação com as anotações, começam a aparecer os processos contábeis, com o surgimento da primeira escola, a Contista, no século XV. Esse pensamento tinha como base o sistema de contas, que tinha a preocupação em registrar dívidas a receber ou pagar, ou seja, o haver e dever. Como tudo era muito simples, apenas as combinaçóes feitas entre os comerciantes e compradores, que era o sistema que eles precisavam na época, eram registradas. Esse sistema é reflexo ainda de um sistema muito primitivo de relações econômicas, onde a escrituração era muito fragmentada e pouca, pois não havia tanta necessidade já que eram poucas as relações existentes, não precisando de uma contabilidade mais complexa, pois ainda o comércio estava no início (SCHMIDT e SANTOS, 2006).

A introdução da técnica contábil nos negócios privados foi uma contribuição de comerciante italianos do sec. XII. Quando apareceu o Tratactus de Computis et Scripturis (Contabilidade das Partidas Dobradas) de Frei Luca Pacioli, publicado em 1494, enfatizando que a teoria contábil do débito e do crédito corresponde a teoria dos números positivos e negativos, obra que contribuiu para inserir a contabilidade entre os ramos do conhecimento humano. Pacioli apesar de ser considerado o pai da contabilidade, não foi o criador das partidas dobradas, o método já era utilizado na Itália, principalmente na Toscana, desde o século XIV (COTRIN et al., 2012, p. 47).

Luca Pacioli enfatizou que "a teoria contábil do débito e do crédito corresponde à teoria dos números positivos e negativos, obra que contribuiu para inserir a contabilidade entre os ramos do conhecimento humano" (ZANLUCA e ZANLUCA, 2017, p. 02).

Segundo Schmidt e Santos (2006, p. 34), Pacioli incluiu esse método no Summa, "por achar bastante necessário ao mercado, que deve saber registrar corretamente suas contas, a partida de crédito e de débito e seus correspondentes e também determinar os lucros e as perdas de todo o negócio". 
Juntamente com esse crescimento que a Europa teve, houve intensificação das navegaçóes marítimas, onde foram se descobrindo novas rotas e novos comércios. Com esses avanços, os comércios foram se desenvolvendo até chegar à Espanha e Portugal, que se tornaram os novos centros comerciais. Esse novo foco fez com que as cidades italianas começassem a decair e entrar em recessão econômica, pois já não era mais de grande interesse, como antes (SCHMIDT e SANTOS, 2006). Após o período, de imenso crescimento econômico, político e social, as cidades italianas, começam a entrar numa época de declínio e juntamente com ela, a contabilidade também vive esse período de estagnação, que foi de 1494 e durou até 1840 , com o surgimento da obra "La Contabilità Applicatta alle Amministrazioni Private e Pubbliche" de Francesco Villa (SCHMIDT, 2000).

O termo "Era da Estagnação", para Hendriksen e Van Breda (1999, p. 45) não é muito apropriado, pois "esse período se iniciou como uma era de descobrimento e encerrou-se como uma era de revoluçáo". Na verdade, durante esse momento, não surgiram outros pensadores, porém foi a época da consolidação contábil, com a divulgação do sistema das partidas dobradas pelo mundo inteiro.

Depois de anos de estagnaçáo, a Inglaterra, passa por um período de crescimento, fruto de uma série de fatos, como o melhoramento da saúde e nutrição da população, devido a boas colheitas e baixo preço do alimento. Esse desenvolvimento fez com que a população aumentasse, e em razão disso, surgisse a necessidade de novos trabalhos para atender aquela demanda crescente. O resultado disso foi o aumento das fábricas e consequentemente, o aumento da produção. Iniciava a era da Revolução Industrial. Diante desses novos fatos que vinham acontecendo, foi crescendo a necessidade de uma contabilidade que englobasse outros requisitos, além do crédito e do débito. Havia a vontade de obter mais informaçóes sobre o que era produzido e os seus custos, ou seja, de um sistema que abrangesse mais dados e que fosse mais complexa ( $\mathrm{SCH}$ MIDT e SANTOS, 2006).

Da necessidade de uma contabilidade mais completa, em 1840, inicia a contabilidade do mundo científico, que dura até hoje, com o surgindo da escola lombarda ou administrativa, com Francesco Villa. Foi uma escola científica, que acreditava que contabilidade não deveria ficar restrita a estruturação, mas ser voltada para o controle da gestáo também. Esses interesses dos autores da época se deram em função ao crescente número de fábricas e aos adventos econômicos da Revolução Industrial, que trouxe uma contabilidade mais complexa e preocupação maior com a administração dos negócios.

O período científico foi aquele em que as doutrinas se agigantaram determinadas, não só em buscar a delimitação de um objeto verdadeiro de estudos para a Contabilidade, mas também, 
especialmente de buscar conhecer a substância gerida pelo ser humano no sentido da satisfação de suas necessidades materiais (SÁ, 1997, p. 55).

Hendriksen e Van Breda (1999, p. 46) consideram este período o segundo importante avanço da contabilidade, pois foi:

Marcado por grandes transformaçốes, uma vez que os detentores do poder, ou seja, os empresários da época começaram a fazer grandes investimentos e, por outro lado, houve a necessidade de contratação de mão-de-obra para trabalhar por mais tempo nas empresas e náo por um período determinado.

Os pensadores da lombarda, influenciados pelo contexto da época, queriam melhorar as informaçóes a serem passadas para os proprietários das fábricas, aliando a contabilidade com a administração, visando a produtividade com a máxima qualidade. Francesco Villa, uns dos principais autores, surge com os princípios econômicos gerais, mostrando a preocupação com a gestão das organizaçóes e defendendo a ideia de que para um novo empreendimento, precisavam-se analisar vários procedimentos e fazer cálculos (SCHMIDT e SANTOS, 2006).

Francesco Villa deu início ao grande progresso da Ciência Contábil:

Extrapolou os conceitos tradicionais de Contabilidade, segundo os quais escrituração e guarda livros poderiam ser feitas por qualquer pessoa inteligente. Para ele, a Contabilidade implicava conhecer a natureza, os detalhes, as normas, as leis e as práticas que regem a matéria administrada, ou seja, o patrimônio (ZANLUCA e ZANLUCA, 2017, p. 08).

Nas próximas décadas não houve fatos marcantes na história, pois a Revolução Industrial ocorria na Inglaterra e os outros países estavam na fase de desenvolvimento e industrialização. Como ainda era início desse novo período, a sociedade alemá, francesa e outras, estavam ainda sem muita evolução, começando um pouco mais adiante, no desenrolar da Revoluçáo. Nesse momento a contabilidade, apresentou escolas como a personalista, que era mais focada com a ideia geral de personalizar as contas, ou seja, as contas deveriam ser abertas por pessoas envolvidas, como pessoa física ou jurídica (SCHMIDT e SANTOS, 2006).

Sá (1997, p. 70) afirma que "o personalismo foi uma corrente que se ligou aos conceitos jurídicos, pessoais, mas, com sérios desenvolvimentos, também, com a administração”. Essa escola foi fundada na segunda metade do século XIX e teve muitos seguidores, como: Francesco Marchi, Giuseppe Cerboni e Giovanni Rossi (SCHMIDT, 2000).

A teoria personalista teve extraordinário impulso com o trabalho desenvolvido por Cerboni, que teve grande interesse pelo aspecto jurídico das relaçôes entre o proprietário e a entidade, 
aspecto esse não abordado no trabalho de Marchi. Marchi foi o iniciador e Cerboni, o construtor da teoria personalista $(\mathrm{SCH}-$ MIDT, 2000, p. 61).

Por volta de 1860, o mundo começa numa nova era, a Segunda Revolução Industrial, onde países como Alemanha, França, Rússia, Itália e EUA começam a se industrializarem, além disso, estavam também em busca de novos territórios e de capitais para financiamento de suas indústrias. Nessa época surge a escola controlista, por volta de 1880 em Veneza, Itália, que tinham pensadores com que acreditava no controle da riqueza administrativa, tendo três fases: gestão, direção e controle (SCHMIDT e SANTOS, 2006).

Como menciona Sá (1997, p. 80) "A escola personalista, Toscana, com grande força e prestígio, encontrou sua contestação ferrenha com o aparecimento da escola de Veneza (controlista)".

$\mathrm{Na}$ Alemanha e Itália, a contabilidade começa a se desenvolver em torno de 1919 e 1920, respectivamente, resultado de fatores como: o desenvolvimento industrial mais tardio de ambas e início das crises, consequência da Revoluçáo Industrial, o que gerou a necessidade de uma contabilidade que trouxesse mais informaçôes. Conforme isso, o desenvolvimento na Escola Alemâ, segundo Schmidt e Santos (2006, p. 123) "se deve, em parte, às crescentes necessidades dos usuários contábeis dos vários setores da contabilidade". E a Escola Italiana, ou aziendal, tinha como ideia a de "mostrar que o fundamento, era ter acrescido a parte cientifica da contabilidade, sendo, a organização, administração e o controle, contribuindo assim, à ciência administrativa e esquecia-se do campo da contabilidade ao levantamento patrimonial, só se lembrando das empresas" (MARQUES, 2010, p. 21).

A partir de 1920, surge a escola americana. "Enquanto declinavam as escolas europeias, floresciam as escolas norte-americanas com suas teorias e práticas contábeis, favorecidas não apenas pelo apoio de uma ampla estrutura econômica e política, mas também pela pesquisa e trabalho sério dos órgãos associativos" (ZANLUCA e ZANLUCA, 2017, p. 08).

"A teoria contábil avançou de acordo com as novas necessidades que se apresentaram, mas foi nos EUA que a contabilidade evoluiu para a prática" (COTRIN et al., 2012, p. 48). A escola norte americana apresentou a divisão da contabilidade em financeira e gerencial, sendo que teve destaque na área financeira com a padronização da contabilidade e com o surgimento de Associaçóes.

O surgimento do American Institut of Certield Public Accountants foi de extrema importância no desenvolvimento da Contabilidade e dos princípios contábeis; várias associaçóes empreenderam muitos esforços e grandes somas em pesquisas nos Estados Unidos. Havia uma total integração entre acadêmicos e os já profissionais da Contabilidade (ZANLUCA e ZANLUCA, 2017, p. 09). 
Conforme Schmidt e Santos (2006, p. 74) a "intensa participação das associaçóes profissionais no desenvolvimento prático e teórico da disciplina”. As associaçôes foram de extrema importância, pois foram elas que desenvolveram a contabilidade, através de duas principais: American Accounting Association (AAA) e Americam Association of Public Accountants (AICPA). Já a área gerencial foi importante, pois ajudou na gestão do capital obtido, em consequência da industrialização, financiamentos e empréstimos, e para adequação das demonstraçóes contábeis. Essa escola foi resultado da necessidade da sociedade, tanto proprietários e quanto banqueiros, que estava precisando de uma contabilidade mais qualificada, padronizada e completa, além das associaçôes, que tiveram inúmeras contribuições como, publicações, criação de revista, proposta, regulamentações e entre outros (SCHMIDT e SANTOS, 2006).

Nos inícios do século atual, com o surgimento das gigantescas corporaçóes, aliado ao formidável desenvolvimento do mercado de capitais e ao extraordinário ritmo de desenvolvimento que os Estados Unidos da América experimentou e ainda experimenta, constitui um campo fértil para o avanço das teorias e práticas contábeis. Não é por acaso que atualmente o mundo possui inúmeras obras contábeis de origem norte-americanas que tem reflexos diretos nos países de economia (ZANLUCA e ZANLUCA, 2017, p. 09).

Assim, com a evolução da contabilidade, surge a Nova História da Contabilidade, formada por uma corrente de pensadores com novas concepções e ideias.

\subsection{NOVA HISTÓRIA DA CONTABILIDADE}

A NHC não constitui certamente uma escola ou corpo unitário de doutrina. Mas os seus partidários compartilham ideias e tendências comuns, que os distanciam da forma tradicional como a História da Contabilidade sempre tinha sido entendida (LIMA, 1999, p. 01).

O aparecimento da "Nova História da Contabilidade", sem dúvida o acontecimento mais importante surgido no seio desta disciplina nos últimos quinze anos e provavelmente causador de grande parte do novo interesse que ela desperta. Os seus impulsos geradores procedem da uniáo entre o novo paradigma crítico radical da investigação contabilística, com a discussão metodológica e epistemológica que agita as águas das ciências históricas desde há cerca de duas dezenas de anos (LIMA, 1999, p. 01).

Este novo paradigma considera a ideia de que a contabilidade "não deve ser estudada unicamente como uma técnica, mas também como uma peça do contexto social e organizativo da sociedade" (ESTEVE, 1997, p. 2). Como argumenta Miller (1994, p. 20), "se quisermos entender plenamente como 
surgiram formas particulares de contabilidade e por que isso lhes é concedido, temos que ir além dos limites da organização e examinar a prática social e institucional da contabilidade".

Chamada também de história "crítica" da contabilidade, ela "baseia seu estudo análise na interpretação das implicaçóes mútuas com o contexto em que tais práticas são realizadas e não com em práticas contábeis isoladas" (MARTIN, 2006, p. 194).

Durante anos, o estudo da contabilidade era relacionado apenas com a concepção de contabilidade como mera prática técnica, sendo explicada apenas por razóes econômicas, como no caso das escolas contábeis. No entanto, recentemente, a literatura assumiu um entendimento, em que ela também pode ser uma prática social, que ultrapassa a ideia anterior de ser uma única técnica neutra (GOMES, 2008).

Miller (1994) menciona que há pelo menos três aspectos diferentes da contabilidade como prática social, que são complementares entre si, são elas: como uma tecnologia; a linguagem e os significados, que são os raciocínios intrínsecos e o domínio da contabilidade. A ênfase em tecnologia significa que a contabilidade é considerada como "uma forma de intervenção, um dispositivo para atuar sobre atividades, indivíduos e objetos de tal forma que o mundo possa ser transformado". Já a racionalidade da contabilidade demonstra que as práticas contábeis são mais do que cálculos numéricos de custos, lucros, perdas e retornos; e "as práticas contábeis são dotadas de um significado que se estende para além da tarefa a que elas são aplicadas” (MILLER, 1994, p. 2-3).

Embora a análise da contabilidade nas organizaçóes continue a ser importante, é necessário "ultrapassar os limites da organização e examinar a prática social e institucional da contabilidade para poder entender como surgiram formas particulares de contabilidade e por que isso lhes é atribuído" (MILLER, 1994, p. 20).

Os novos historiadores consideram a contabilidade mais como um fenômeno cultural do que simplesmente como uma prática técnica e são estão mais predispostos a vê-la como um instrumento de poder e dominaçáo do que como um conjunto de ideias e técnicas sem valor para implementar e monitorar contratos livremente (GOMES, 2008).

Ao invés de ver a história da contabilidade como uma evolução natural das tecnologias administrativas, cada vez mais será vista como a formação de um determinado complexo de racionalidades e modos de intervençáo entre muitos, um complexo que foi formado de diversos materiais e em relação a uma gama heterogênea de questóes e eventos (CARNEGIE; NAPIER, 1996, p. 7).

Os esforços dos novos pesquisadores náo estavam na busca de soluçóes para problemas específicos, mas sim em problematizar e desconstruir os desenvolvimentos nas práticas contábeis, identificando seus efeitos sobre o funciona- 
mento organizacional e social, no entendimento de problemas, prioridades e soluções, entre outros (CARMONA, EZZAMEL e GUTIÉRREZ, 2004). Eles estão preocupados com "re-orientaçóes, transformações e reversões que o tempo instarou, ao invés de procurar voltar no tempo para detectar uma continuidade ininterrupta que nos une ao nosso passado" (MILLER e NAPIER, 1993, p. 632).

Chamada também de história "crítica" da contabilidade, ela ampliou as áreas nas quais a contabilidade é compreendida e trouxe novos atores para a análise, como o estado e as instituiçôes. Essas contribuiçóes podem ajudar a melhorar a compreensão das conexóes entre as concepçóes de contabilidade adotadas por pesquisadores de contabilidade contemporânea e as escolas de pensamento adotadas por pesquisadores de contabilidade histórica (GOMES; 2008; p. 497).

O novo paradigma fez com que os historiadores pensassem além das definições convencionais de contabilidade, de modo que uma visão muito mais abrangente foi desenvolvida para alcançar um maior conjunto de práticas de quantificação, valorização e representação (CARMONA, EZZAMEL e GUTIÉRREZ, 2004).

Dessa forma, estes novos estudos históricos podem ser uma importante fonte de informação para ajudar a melhorar a compreensão dos papéis da contabilidade nas organizaçóes e na sociedade, particularmente nos processos de mudança contábil que se tornaram importantes questóes de pesquisa dentro da concepção de contabilidade como prática social (GOMES, 2008, p. 497).

Os novos historiadores da contabilidade, conforme Carnegie e Napier (1996, p.7) "não são amplamente receptivos à abordagem tradicional de explicar modos específicos de contabilidade por referência exclusivamente a racionalidades econômicas". Mas cabe ressaltar que os novos historiadores "são obrigados a usar os trabalhos dos historiadores tradicionais da contabilidade no desenvolvimento da literatura, em vez de ignorar essas contribuiçóes e, portanto, reinventar o campo como resultado" (GOMES, 2008, p. 480).

Dessa maneira, esta concepção social nas últimas décadas expandiu o domínio da contabilidade, aumentando o escopo limitado promovido pela história tradicional. Entretanto, conforme Burchell et al. (1994, p. 540):

Como resultado, pouco se sabe de como as práticas técnicas de contabilidade estáo ligadas ao social, de como as forças sociais mais amplas podem afetar e mudar a contabilidade, e de como a própria contabilidade funciona no domínio do social, influenciando, além de apenas reagir para isso.

Assim, a nova história da contabilidade demonstrou o valor de atribuir papéis à prática contábil além da pura economia racional. Ou seja, de modo que não precisa mais considerar a contabilidade como um bem puramente econômico. Mas também não necessariamente excluindo, pois tais explicações do surgimento e do funcionamento das práticas contábeis ajudam a liberar o pensamento (MARTÍN, 2006). 


\subsection{DIFERENÇA ENTRE A HISTÓRIA TRADICIONAL E A NOVA HISTÓRIA}

A contabilidade apresenta duas diferentes dimensóes: sendo por um lado, a Contabilidade Tradicional, em que os pesquisadores enfatizam uma visão mais técnica, observado ela como um conjunto de procedimentos que são utilizados para satisfazer os requisitos e necessidades de seus usuários. E por outro lado, a Nova Contabilidade, em que pesquisadores destacam a dimensão social e institucional, tentando entender e explicar os atributos da contabilidade, assim, como determinar os impactos sobre o funcionamento organizacional e social, requerendo uma maior compreensão de como a ela configura seu ambiente e de como, por sua vez, o meio ambiente a molda (GOMES, 2008).

Sendo assim, Gomes (2008) menciona a principal divergência entre as duas percepçóes:

Os especialistas em contabilidade que se sentem confortáveis com a contabilidade apenas como uma prática técnica normalmente ficariam confortáveis com as histórias contábeis tradicionais. Por outro lado, os especialistas em contabilidade que se sentem confortáveis com a noção de contabilidade como prática social normalmente ficariam confortáveis com novas histórias contábeis (GOMES, 2008, p. 481).

Entre alguns pontos de contraste entre a História Tradicional e a Nova História da Contabilidade são: no primeiro ponto, o paradigma tradicional, a história diz respeito essencialmente à política. E por outro lado, a nova história começou a se interessar por virtualmente toda a atividade humana. Tudo tem uma história, ou seja, tudo tem um passado que pode em princípio ser reconstruído e relacionado ao restante do passado (BURKE, 1992).

Outra diferença importante é em relação à visão, na qual a história tradicional oferece uma visáo de cima, no sentido de que tem sempre se concentrado nos grandes feitos dos grandes homens, estadistas, generais ou ocasionalmente eclesiásticos. Ao resto da humanidade foi destinado um papel secundário no drama da história. Entretanto, por outro lado, vários novos historiadores estão preocupados com a história vista de baixo, ou seja, com as opinióes das pessoas comuns e com sua experiência da mudança social (BURKE, 1992).

Para Martín (2006), a nova visão da história a partir de baixo, ocorre quando:

Procuramos identificar a importância da prática contábil para os comerciantes medievais ou mercantis do capitalismo nascente, por exemplo; ou ao perguntar sobre o papel das mulheres na formação e desenvolvimento da profissão contábil, o papel de outras formas de representaçáo do que a dupla entrada, como a entrada única ou as diferentes formas contábeis das sociedades antigas (comprimidos, argila), quipus, entre outros (MARTÍN, 2006, p. 190). 
Outro ponto divergente é sobre o fato de que, no modelo tradicional, as fontes eram constituídas por documentos, registros oficiais que expressam o ponto de vista oficial. A Nova História, além de aumentar o conceito de fontes, faz críticas como em relação a tempo e fatos históricos e propóe uma história problematizada e não simplesmente automática (MAIA et al, 2011).

Segundo o paradigma tradicional, a História é objetiva. A tarefa do historiador é apresentar aos leitores os fatos, ou, a forma como eles aconteceram.

$\mathrm{Na}$ nova história, os historiadores deslocam o "ideal da Voz da História para aquele da heteroglossia, definida como 'vozes variadas e opostas'”. A história nova reflete uma possibilidade para se "considerar mais seriamente as opinióes das pessoas comuns sobre seu próprio passado" do que comumente faziam os historiadores na história tradicional (MAIA et al, 2011, p. 140).

De forma resumida, os seis pontos de diferença entre a antiga e a nova história, mencionados por Burke (1992), conforme quadro abaixo:

Quadro 1: Diferenças entre História Tradicional x Nova História

\begin{tabular}{cll}
\hline Diferenças & \multicolumn{1}{c}{ História Tradicional } & \multicolumn{1}{c}{ Nova História } \\
\hline 1 & História diz respeito à política; & $\begin{array}{l}\text { Toda atividade humana pode ser } \\
\text { objeto da história; }\end{array}$ \\
\hline 2 & $\begin{array}{l}\text { Pensam na história como } \\
\text { essencialmente uma narrativa } \\
\text { dos acontecimentos; }\end{array}$ & $\begin{array}{l}\text { Está mais preocupada com a } \\
\text { análise das estruturas; }\end{array}$ \\
\hline 3 & $\begin{array}{l}\text { Oferece uma visão de cima, no } \\
\text { sentido de que tem sempre se } \\
\text { concentrado nos grandes feitos } \\
\text { dos grandes homens, estadistas, } \\
\text { generais ou eclesiásticos; }\end{array}$ & $\begin{array}{l}\text { Estáo preocupados com a história } \\
\text { vista de baixo, com as opiniôes das } \\
\text { pessoas comuns e sua experiência } \\
\text { de mudança social; }\end{array}$ \\
\hline 4 & $\begin{array}{l}\text { A história deveria ser baseada } \\
\text { em documentos oficiais escritos; }\end{array}$ & $\begin{array}{l}\text { Expóe as limitaçóes de tipo } \\
\text { de documento, examinando } \\
\text { maior variedade de evidências, } \\
\text { atribuindo menorênfaseàs fontes } \\
\text { escritas e maior relevância ao uso } \\
\text { da história oral, iconografia e } \\
\text { vestígios arqueológicos; }\end{array}$ \\
\hline 5 & $\begin{array}{l}\text { Preocupa-se com as açốes dos } \\
\text { indivíduos; }\end{array}$ & $\begin{array}{l}\text { Considera relevantes movimen- } \\
\text { tos coletivos e individuais; }\end{array}$ \\
\hline 6 & $\begin{array}{l}\text { A história é objetiva, e a tarefa } \\
\text { única do historiador éacrescentar } \\
\text { aos seus leitores os fatos. }\end{array}$ & $\begin{array}{l}\text { Mostra a inevitabilidade da } \\
\text { falta de isençấo ao olhar sobre o } \\
\text { passado. }\end{array}$ \\
\hline
\end{tabular}

Fonte: Adaptado de Burke (1992, p. 2-4). 
Diferente de Burke, Esteve (1997) menciona muito sinteticamente apenas duas características que distinguem as Histórias da Contabilidade:

Em primeiro lugar a perda de convicção na possibilidade de se alcançar a objetividade, no estudo e descrição dos factos históricos, o que dá origem a que a interpretação dos factos ganhe a primazia sobre a apresentação dos mesmos. Em segundo lugar, o abandono de uma espécie de darwinismo histórico-contábil, que consiste em pensar a contabilidade como as restantes atividades humanas, sujeita a um processo mais ou menos linear de progresso contínuo. (ESTEVE, 1997, p. 2).

Outro fato em que se diferem as duas histórias é referente ao debate sobre as origens versus gênese da contabilidade. Os pesquisadores tradicionais estáo principalmente preocupados com as origens e a evoluçáo, enquanto que os novos argumentam que essas áreas de interesse são problemáticas (CARMONA, EZZAMEL e GUTIÉRREZ, 2004).

Sobre a visão tradicional:

O pesquisador normalmente procuraria identificar a "origem" das inovaçôes na prática contábil e, portanto, a história é vista como uma coleção de eventos que podem ser organizados sistematicamente e cronologicamente, começando com o 'primeiro' evento e avançando gradualmente escala temporal (CARMONA, EZZAMEL e GUTIÉRREZ, 2004, p. 38).

Já na nova abordagem, a busca pelas origens das inovaçóes contábeis é considerada repleta de problemas e infrutíferas, pois não existe uma razão a priori porque um determinado evento (de fato, qualquer evento) deveria ter ocorrido em qualquer momento ou lugar (EZZAMEL et al, 1990, apud CARMONA, EZZAMEL e GUTIÉRREZ, 2004, p. 157).

O histórico é visto como sendo muito mais do que simplesmente uma agregação de eventos. Os pesquisadores da NAH buscarão se concentrar em "gênese", pelo que, ao invés de olhar para trás no tempo, tentando descobrir origens, o pesquisador pretende descobrir o cenário sociopolítico que causa ou dá origem a práticas contábeis específicas. (CARMONA, EZZAMEL e GUTIÉRREZ, 2004, p. 38).

Ao contrário da história clássica, a nova compreende várias abordagens heterogêneas para o estudo da história contábil:

Uma proliferação de metodologias, um questionamento de noções recebidas, como progresso e evolução, um alargamento do escopo, uma nova atenção à linguagem e racionalidades que dão significado às práticas contábeis e uma mudança de foco longe de personagens invariantes como o livro-detentor e decisor para a preocupação com transformaçóes mais amplas no conhecimento contábil (MILLER, HOPPER e LAUGHLIN, 1991, p. 395). 
Entretanto, vale ressaltar que mesmo havendo divergências fundamentais entre as duas concepçóes, histórico tradicional e novo, ambas puderam contribuir para enriquecer e aprofundar esse campo de pesquisa e compreensão da prática contábil (GOMES, 2008).

\section{CONSIDERAÇÓES FINAIS}

A Contabilidade, assim como a sociedade, teve o seu desenvolvimento evoluindo gradual e lentamente, que continua até hoje. É possível afirmar que ambas estão relacionadas, na qual o crescimento da Contabilidade ocorreu de acordo com as necessidades humanas, políticas e econômicas.

A história da Contabilidade perpassa pelas décadas. Percebe-se então, que o seu processo ao longo do tempo manteve-se sempre em constante evolução. Assim, o objetivo deste estudo foi conhecer a Nova História da Contabilidade e consequentemente apresentar quais as características que a distinguiram da História Tradicional da Contabilidade.

Diferente da História Tradicional observa-se que uma nova corrente começou a tomar força, a da Nova História da Contabilidade, que apresentou uma visão contrária dos pensamentos clássicos, preocupando-se com o social e o institucional e não mais apenas com o econômico e político. Os autores dessas novas concepçóes, mesmo que náo compartilhem de ideias e posicionamentos semelhantes perante a História, eles acreditam que a contabilidade deve ser vista como um todo, e não meramente de forma isolada.

Dessa forma, analisando as principais escolas do pensamento contábil, percebe-se que desde a primeira a surgir, a Escola Contista, elas desenvolveram de acordo com a necessidade que iria surgindo da sociedade. Nota-se que quando o mundo tinha um comércio primitivo, o processo contábil era muito rudimentar, apenas contas de debitar e creditar. Mas conforme ela foi evoluindo, foi cada vez mais se tornando complexas as informaçóes que eram solicitadas pelos usuários, o que foi gerando uma contabilidade mais completa.

Entretanto, vale ressaltar que as escolas contábeis fazem parte da história da contabilidade tradicional, pois se preocupavam apenas em cumprir com as necessidades dos seus usuários, onde cada vez ficava mais forte a ideia de posse $\mathrm{e}$ propriedade. Assim, consequentemente, o homem passa a se preocupar em conservar e aumentar o patrimônio, com o objetivo de ver sua riqueza aumentar.

Portanto, divergente em algumas características, destacam-se entre elas: a Nova História tem um pensamento mais abrangente sobre a contabilidade clássica, saindo da visão limitada que a anterior passava para um pensamento social e tendo uma visáo de baixo, o que demonstra que ela náo vê apenas os grandes feitos, as batalhas e a política, mas como também enxerga o homem como pessoa comum e como personagem desta história. Outro ponto relevan- 
te na nova dimensão são os vários tipos de documentos examinados, além da história oral como forma de compreender melhor o passado, e consequentemente, expor uma visão mais ampla.

Apesar disso, percebe-se que ambas as visóes tiveram sua importância. Contudo, apesar das discordâncias entre os pensamentos tradicionais e novos, elas têm seu lugar na pesquisa de história e têm potencial para aumentar nosso conhecimento sobre o passado contábil. Por este motivo, deverá ter o seu passado sempre relembrado, pois sem este desenvolvimento náo teria sido possível o novo, e para que os futuros profissionais possam entender de que forma a contabilidade iniciou e de que maneira os novos pensadores podem influenciar para trazer novas compreensóes a essa ciência.

Portanto, este estudo aqui realizado não se encerra. Pelo contrário, abre caminho para que sejam feitas novas pesquisas sobre o assunto, que ainda é pouco explorado, principalmente por pesquisadores brasileiros. Como sugestão para futuras pesquisas, pode-se colocar que estas se aprofundem mais em assuntos específicos ou pontuais na evolução da história, tanto pela tradicional quanto para a nova. Por exemplo, um estudo sobre o entendimento e aceitação dos profissionais contábeis sobre o conhecimento da Nova História da Contabilidade e como ela pode influenciar o pensamento dos novos pesquisadores e historiadores.

\section{REFERÊNCIAS}

BARROS, J. D. Teoria da história: Volume I. Princípios e conceitos fundamentais. Petrópolis: Vozes, 2011.

BAUER, M. W.; GASKELL, George. Pesquisa Qualitativa com texto, imagem e som. 10a. Ed. Petrópolis: Vozes, 2012.

BERTALAN, N.; NAPIER, J.. The emergence of the 'new accounting history. Working paper, School of Management, Royal Holloway University of London, July, 2013.

BURCHELL, S.; CLUBB, C.; G. HOPWOOD, A.. Accounting in its Social Context: Towards a History of Value Added in the United Kingdom. Accounting History: Some British Contributions. Oxford: Clarendon Press, p. 539-589, out. 1994.

BURKE, P. A escrita da história: novas perspectivas. São Paulo: Editora UNESP, 1992.

CANABARRO, I. S. Teoria e métodos da história I. Ijuí, Rio Grande do Sul: Unijuí, p. 98, 2008.

CARMONA, S.; EZZAMEL, M.; GUTIÉRREZ, F. Traditional and New Accounting History Perspectives. DE COMPUTIS Revista Española de Historia de la Contabilidad. n. 1, Diciembre, 2004. 
CARNEGIE, G. The present and future of accounting history. Accounting, Auditing \& Accountability Journal, v. 27, n. 8, p. 1241-1249, 2014.

CARNEGIE, G.; NAPIER,C. J.."Critical and Interpretive Histories: Insights into Accounting's Present and Future Through its Past", Accounting, Auditing and Accountability Journal,v. 9, n..3, p. 7-39, 1996.

CASTRO, H. História social. In: CARDOSO, C. F.; VAINFAS, R.. Dominios da história: ensaios sobre teoria e metodologia. Rio de Janeiro: Elsevier, 1997.

CERVO, L.; BERVIAN, A.. Metodologia cientifica: para uso de estudantes universitários. 4. ed. São Paulo: Mcgraw-Hill, 1996.

CLEMENTE, W. História Política e a "Nova História": um breve acerto de contas. Cadernos UniFOA, Volta Redonda - RJ, v. 16, p. 45-50, ago. 2011. Disponível em: <http://web.unifoa.edu.br/cadernos/edicao/16/45.pdf>. Acesso em: 26 nov. 2017.

COSTA, A. M.; BARROS, D. F.; MARTINS, Paulo Emílio Matos. Perspectiva histórica em administração: novos objetos, novos problemas, novas abordagens. RAE-Revista de Administração de Empresas, São Paulo, v. 50, n. 3, p. 288299, jul/set. 2010. Disponível em: <http://www.scielo.br/scielo.php?script=sci_arttext\&pid=S0034-75902010000300005\&lng=en\&nrm $=$ iso \&tlng=pt $>$. Acesso em: 29 nov. 2017.

COTRIN, A. M. et al. A evolução da contabilidade e o mercado de trabalho para o contabilista. Revista Conteúdo, Capivari, v. 2, n. 1, jan./jul. 2012. Disponível em: <http://www.conteudo.org.br/index.php/conteudo/article/ viewFile/70/63>. Acesso em: 29 nov. 2017.

ESTEVE, E. H. HISTÓRIA DA CONTABILIDADE: PASSADO RUMO AO FUTURO. Revista de Contabilidade e Comércio, Figueira da Foz, Portugal, v. 55, n. 216, out. 1997. Disponível em: <http://www.apotec.pt/fotos/editor2/HISTORIA DA CONTABILIDADE.pdf>. Acesso em: 27 out. 2017.

FALCON, F. J. C. História e poder. In: CARDOSO, C. F; VAINFAS, R. Dominios da história: ensaios sobre teoria e metodologia. Rio de Janeiro: Elsevier, 1997.

GIL, Antonio Carlos. Como elaborar projetos de pesquisa. 4. ed. São Paulo: Atlas, 2009

GOMES, D. The interplay of conceptions of accounting and schools of thought in accounting history. Accounting History, [S.L], v. 13, n. 4, p. 479-509, nov. 2008. Disponível em: <http://journals.sagepub.com/doi/ abs/10.1177/1032373208095480>. Acesso em: 30 nov. 2017. 
IUDÍCIBUS, S.; MARTINS, E.; CARVALHO, L. N.. Contabilidade: aspectos relevantes da epopeia de sua evoluçâo. Revista Contabilidade \& Finanças, v. 16, n. 38, p. 7-19, 2005.

HENDRIKSEN, E..; VAN BREDA, M.. Teoria da Contabilidade. Traduzido por Antônio Soratto Sanvinvente, São Paulo: Atlas, 1999.

LE GOFF, J.. História e memória. Campinas: Unicamp, 1992.

LIMA, A. HISTÓRIA TRADICIONAL DA CONTABILIDADE. Revista de Contabilidade do Mestrado de Ciências Contábeis do UERJ, Rio de Janeiro, v. 4, n. 1, jan. 1999. Disponível em: <http://www.e-publicacoes.uerj. br/index.php/rcmccuerj/article/view/7181>. Acesso em: 02 nov. 2017.

LIMA, M. C.. A engenharia da produçáo acadêmica. $2^{\text {a }}$ ed. São Paulo: Saraiva, 2008.

LITTLETON, A. C.. Accounting Evolution to 1900. Second edition, New York: Russell \& Russell, 1966.

MAIA, A. M. R. et al. Pesquisa Histórica: possibilidades teóricas, filosóficas e metodológics para análise de fontes documentais. História de Enfermagem: Revista Eletrônica-HERE, Brasília, v. 2, n. 1, p. 137-149, 2011.

MARQUES, W. L.. Contabilidade Geral Segundo a Lei 11638/2007 das SAs. Gráfica Vera Cruz. Cianorte - Paraná, 2010.

MARTÍN, F. Q.. Historia de la Contabilidad: Una revisión de las Perspectivas Tradicionales y Críticas de Historiografía Contable. Revista Facultad de Ciencias Económicas - Investigación y Reflexión, Colômbia, v. 14, n. 1, p. 187-202, jun. 2006. Disponível em: <http://www.redalyc.org/articulo. oa?id=90900110>. Acesso em: 04 nov. 2017.

MARTINS, G. A.; THEÓPHILO, R.. Metodologia da investigação científica para ciências sociais aplicadas.2. ed. São Paulo: Atlas, 2009.

MILLER, P. "Accounting as a Social and Institutional Practice: An Introduction”, in Hopwood, A.G. Miller, P. (eds.), Accounting as Social and Institutional Practice, Cambridge: University Press,p. 1-39, 1994.

MILLER, P.; HOPPER, T.; LAUGHLIN, R. The new accounting history: an introduction. Accounting, Organizations and Society, v. 16, n. 5/6, p. 395-403, 1991.

MILLER, P.;NAPIER,C.J ."Genealogies of Calculation”, Accounting, Organizations and Society, v. 18, n. 7/8, p. 631-647, 1993.

MINAYO, S.; et al. Pesquisa Social: Teoria método e criatividade. Petrópolis, RJ: Vozes, 1994. 
MIRANDA, G. J., et al. Pesquisa em educação contábil e as preferências dos doutores da área: em casa de ferreiro, o espeto é de pau?. Revista Contabilidade \& Finanças USP, v. 24, n. 61, 2013.

MORGAN, G; WILLMOTT, H. “The 'New' Accounting Research: On Making Accounting More Visible". Accounting, Auditing and Accountability Journal,v. 6, n. 1,p. 3-36, 1993.

PADILHA, M. C. S.; BORENSTEIN, M. S. O método de pesquisa histórica na enfermagem. Texto \& Contexto Enfermagem, v. 14, n. 4, p. 575-584, 2005.

PELEIAS, I. R. et al. Evolução do ensino da contabilidade no Brasil: uma análise histórica. Revista de Contabilidade e Finanças USP, São Paulo, v. 30, p. 19-32, 2007.

RICARDINO FILHO, Á. A.; MARTINS, G. A. O livro caixa da ordem terceira de São Francisco em Recife (Brasil): séculos XVII e XVIII. Revista Contabilidade \& Finanças, v. 14, n. 33, p. 78-89, 2003.

SÁ, A. L. História Geral e das Doutrinas da Contabilidade. São Paulo: Atlas, 1997.

SCHMIDT, P. Historia do pensamento contábil. Porto Alegre. Bookman, 2000. SCHMIDT, P.; SANTOS, J. L. História do pensamento contábil. São Paulo: Atlas, 2006, v. 8.

. Gênese dos controles contábeis. Anais do II Congresso de Contabilidade da UFRGS. Linha Pesquisa e História da Contabilidade. Universidade Federal do Rio Grande do Sul, Porto Alegre, 19 e 20 de outubro de 2017.

. The application of Inca khipu as an accountability and managerial control tool. Revista Brasileira de Gestáo de Negócios, v. 19, n. 66, p. 613-626, 2017.

SILVA, R. C.. História da escola brasileira de contabilidade até o surgimento da primeira doutrina contábil positiva. Contaduria Universidad de Antioquia, n. 68, p. 313-332, 2017.

VERGARA, S. C. Métodos de pesquisa em administraçáo. 2. ed. São Paulo: Atlas, 2006.

ZANLUCA, J. C.; ZANLUCA, J. S.. História da Contabilidade. Disponível em: <http://www.portaldecontabilidade.com.br/tematicas/historia.htm>. Acesso em: 15 set. 2017. 
